\title{
Does fitness enhance learning/academic performance?
}

\author{
Paulina Górska, Jana Krzysztoszek, Agata Korcz, Michał Bronikowski \\ Department of Didactic of Physical Activity, University School of Physical Education, Poznań, Poland
}

\begin{abstract}
Summary
The interest in the relationship between physical fitness and academic performance is still considerable. However, more advanced research is required to better understand this relationship. Therefore, the purpose of the current review is to describe the state of knowledge of the relationship between physical fitness and academic performance. Furthermore, this relationship is explored with reference to five components of physical fitness, asking which ones have the most beneficial effect on maintaining and improving learning outcomes. In this review, we emphasize studies that advance the understanding of this issue, which is still incomplete. These studies offer hope of deeper understanding of the type of selected physical fitness components and their impact on academic performance. Further research into the association between components of physical fitness such as flexibility, strength and endurance of muscles and academic performance in children, while controlling for important covariates, is needed.
\end{abstract}

\section{Key words: Physical fitness components - Exercise - Aerobic fitness - Flexibility - Muscular fitness - Learning - Academic achievement/performance}

\section{Introduction}

Physical fitness, health, and quality of life are closely related. The human body has been designed to move for optimal functioning and to avoid diseases so it requires regular physical activity. Physical activity is also essential for proper development and maintaining the health of children and adolescents. The World Health Organization (2010) recommends that the school-age developmental population should exercise at a moderate to intensive level daily for 60 minutes or longer, in age-appropriate, enjoyable, and multi-tasking forms. It is recommended that most of the exercises should be aerobic. However, this should be with exercises that strengthen the bones and muscles at least 3 times a week. Particular emphasis should be placed on the development of motor skills of young people [13]. Compliance with the recommended level of physical activity is important for improving cardiorespiratory fitness, counteracting overweight and obesity, and for better bone mineralization at an early age [22, 39]. In addition, regular physical activity brings many other social and psychological benefits, reduces the risk of depression, and improves self-esteem [5, 39].

With regard to the benefits of physical exercise, it is worth paying attention to its impact on academic performance achieved by children and adolescents at school. Particular attention has been paid to the fact that both health and performance at school are important in a child's life and that health problems can affect them. The results of subsequent studies in this area provided contradictory evidence on the subject of the analyzed relationship. Keeley and Fox [25], based on a systematic review in 2009, analyzing the potential of physical fitness and exercises to improve the cognitive functions, learning, and school performance of children, concluded that there is a weak positive association. Bezold et al. [4], in a longitudinal study which included a group of 83,131 junior high school students from New York, observed that both boys and girls who improved their physical fitness had better results at school. Specifically, academic performance improved in the subsequent year for both boys and girls who increased their fitness level by more than 20 percentile points relative to the other students whose fitness did not change. Conversely, male and female students whose fitness level decreased by more than 20 percentile points relative to other students had a decline in academic performance compared with their peers whose fitness did not change [4]. Evidence for a positive relationship between physical fitness and school results was also provided by a review of research by Donnelly et al. [11]. Analyzing 32 studies, Donnelly et al. [11] stated that physical fitness 
has a positive effect on cognitive functions and school performance. He stressed, however, that the results of the study were varied and the evidence comes primarily from outcomes of uncontrolled or non-randomized trials or from observational studies. Some studies found positive associations between physical fitness and mathematics, but not reading or spelling, while other studies found the opposite $[24,30,35]$. In other studies, an inverse relationship was found. The results of the research were also different in terms of the gender of the respondents; some of them showed a positive association for physical fitness and academic performance only in the group of girls $[42,43]$.

The association of physical fitness and academic performance involves the impact on blood circulation, specifically in the brain, both during, but more importantly, after exercise. Trudeau and Shephard [41] and Rosenbaum et al. [33] show that there are several mechanisms by which physical motion can affect the physiology of the brain. Physical activity increases the number of capillaries in the brain, increases blood flow, and stimulates the production of neurotrophins and the growth of nerve cells in the hippocampus (center of learning and memory, neurotransmitter levels, development of nerve connections, density of neural network and brain tissue volume). These physiological changes in the context of learning at school can contribute to increased attention, improved processing, storage and retrieval of information, as well as better coping [33, 41].

Analyzing the current scientific achievements investigating the relationship between physical fitness and academic performance, it can be stated that the results of scientific research are ambiguous. The authors emphasize that this issue requires further in-depth research. The questions of whether the relationship between physical fitness and school performance refers to a specific type of physical exercise and which ones have the most beneficial effect on maintaining and improving learning outcomes are addressed. We follow this with a review of recent literature in selected physical fitness components and their influence on academic performance for a better understanding of their relationships.

\section{Aerobic fitness and academic performance}

Aerobic fitness is defined as the overall capacity of the respiratory and cardiovascular system and also the ability to carry out long strenuous exercises. The maximal oxygen consumption $\left[\mathrm{VO}_{2} \mathrm{max}\right]$ attained during a graded maximal exercise to voluntary exhaustion has been recognized by the WHO as the best indicator of cardiorespiratory fitness [31].

Cardiorespiratory fitness appears to be associated with cognitive functions of children and adolescents $[15,28]$ and is identified as a factor that might be related to cognitive control [6, 19, 21], brain plasticity [18], better cognitive abilities $[7,16,20]$, and improvement of memory $[17,30,34]$. The beneficial effect of physical exercise on cognitive functions is probably the result of the induction of angiogenesis in the motor cortex, resulting in better blood flow and cerebral vascularization [18]. Improvement of neurocognitive functions may be associated with better academic performance in children and adolescents, which has been presented in several studies [7, 10, 35]. Haapala [15] also concludes that children with greater cardiorespiratory fitness probably have a greater hippocampus volume and greater neuroelectric efficiency when performing cognitive tasks. Singh et al. [38] confirmed the positive effect of improved cardiorespiratory fitness on the level of attention and concentration in the classroom, as well as better behavior of students in the field of learning.

The positive relationship between cardiorespiratory fitness and academic performance was also confirmed by the latest systematic review of articles published in 2017 by Santana et al. [34]. From a total of 45 studies, 25 report a positive association between physical fitness components and academic performance in young people and 20 describe a single association between aerobic fitness and learning outcomes, published between 1990 and 2016. The results suggest strong evidence of positive associations between cardiorespiratory fitness and academic performance for cross-sectional studies and uncertain evidence for longitudinal ones [34]. However, the authors stressed that many of the studies had relatively small samples or used correlational methodologies that cannot provide evidence.

An interventional study investigating the relationship between cardiorespiratory fitness and school performance was conducted in Portugal with a group of 1286 fifth-, sixth-, and seventh-grade students, age 11 to 14 years, from 14 schools for 3 years. [33]. Students who improved their cardiorespiratory fitness as a result of intervention were more likely to achieve better grades (especially in their language arts and foreign languages) at school compared to those who did not improve. Evidence for a positive $r$ elationship between cardiorespiratory fitness and language arts tests was also provided by Oliveira et al. in 2017 [30]. The study was of a cross-sectional nature ( $\mathrm{n}=640$ youngsters, $10-18$ years) and the relationship between aerobic fitness and the results of the language arts and mathematics were evaluated. The authors observed that a higher level of circulatory and respiratory efficiency is associated with better grades in the language arts, but not in mathematics. Other findings came from Kao et al. [24] based on a study on a group of 79 children aged 9-11, assessing their aerobic fitness using a graded exercise test; a muscular fitness assessment composed of upper body, lower body, and core exercises; a serial n-back task to assess working memory; and a school performance test of 
mathematics and reading. The results showed that aerobic fitness was associated with mathematics performance in the category of algebraic functions. The authors also noted that better circulatory and respiratory efficiency is associated with better results in tasks in which working memory is involved [24]. Pindus et al. [32] found that aerobic fitness, rather than daily moderate-to-vigorous physical activity (MVPA), was positively associated with childhood ability to manage perceptual interference and spelling.

Studying the correlation between aerobic fitness and academic performance requires clarification of several issues. Studies that were carried out using the linear method $[9,12,42]$ indicate a positive relationship between the analyzed variables. At the same time, the authors emphasize that the type of method with which the circulatory and respiratory capacity of students has been measured is also important. Evidence of the relevance and importance of this factor is the discrepancy in the results of research by Dwyer et al. [12] and Wittberg et al. [44]. Dwyer et al. [12] observed the relationship between the analyzed variables using a bicycle ergometer as opposed to measuring using a 1.6-meter test. Meanwhile, Wittberg et al. [44] found a relationship between academic performance and the time achieved by students in one-mile-runs. Shorter time was associated with better academic results. However, when measuring cardiorespiratory function by shuttle run, Wittberg et al. [44] found a positive relationship only in relation to girls.

The question of the impact of aerobic exercises on the school results achieved in specific areas is also not explained. Some studies, such as those performed by Oliveira et al. [30], suggest that aerobic exercises and better circulatory and respiratory efficiency positively affect only the results of language arts, while they are not related to the assessment of mathematics, which was also confirmed by Sardinah et al. [35]. The study of Kao et al. [24] however only suggests a link with mathematics. Further research requires clarification of this issue and an explanation of the discrepancies. This is necessary if the research results are to be used in the future in planning effective teaching.

Regular aerobic exercise and the related better cardiorespiratory fitness probably have a beneficial effect, not only on the health of students, but also on their results achieved at school [24, 30, 33, 34]. However, this issue requires a greater amount of interventional research of cause-and-effect relationships, as the results of currently available research in this area are ambiguous. This issue is extremely important from the point of view of planning an effective teaching system. Confirmation of a positive relationship between cardiorespiratory fitness and academic performance may lead physical education teachers and classroom teachers of the early developmental phases to increase the number and participation in the total number of hours of classes including aerobic exercise.

\section{Flexibility and academic performance}

Another important element of physical fitness is flexibility. It can be defined as the capability to move a joint through its complete span of motion [40].

Van Dusen et al. [42], in a study of 254,743 students from 13 different schools in Texas, also observed that there was a positive correlation between flexibility and school performance. This correlation was dependent on gender and a stronger relationship between the analyzed variables (especially in reading) was observed in girls. Wang et al. reached similar conclusions, [41] based on a study of 1,339 pupils from 4 to 6 elementary schools from southern Taiwan. They showed that flexibility has a positive effect on academic performance in the areas of language arts, mathematics, and exact sciences. Van Dusen et al. [42] also observed a stronger relationship in girls. The results were similar to other empirical studies $[1,8,26]$. A later study by Bass et al. [2], completed on a group of 838 high school students from grades 6-8 from Illinois, USA, provides other results in this area. Researchers found that a positive correlation between physical fitness (4 components were analyzed: muscle strength, muscular endurance, flexibility, and cardiorespiratory fitness) and academic results in school was only significant in relation to cardiorespiratory fitness and muscle endurance. However, they did not find such a relationship in regard to the flexibility of either gender, while at the same time emphasizing that the gender factor is very important. In the group of boys, cardiorespiratory fitness and muscle endurance had a positive effect on the results in the field of mathematics and reading. In the group of girls, this relationship was observed only in relation to cardiorespiratory fitness, which confirms that the relationship between flexibility and academic performance remains uncertain and requires further research. Establishing a positive relationship between the analyzed variables could be the basis for taking into account more hours in the field of stretching exercises having a positive impact on flexibility and academic performance in current school programs.

\section{Muscle strength and endurance and academic performance}

Muscular fitness has health benefits for children, including improved bone health, decreased central adiposity, and lower metabolic risk factors [38], which have been associated with enhanced cognitive control $[23,36]$. Furthermore, Benson et al. [3] claimed that childhood muscular fitness is also associated with lower insulin resistance, which Gonzales et al. [14] found to relate to cognitive functions such as working memory. 
Investigating the relationship between muscle strength and endurance and academic performance in a group of 79 preadolescent children between the ages of 9 and 11 years from the East-Central Illinois region, Kao et al. [24] stated, as did Bass et al. [2], that muscle strength and endurance in addition to cardiorespiratory fitness, are most strongly associated with school performance. In addition, the existence of differences in the occurrence of correlations between muscle strength and endurance in relation to gender was also emphasized by Wang et al. [43]. In relation to muscle strength and endurace, they observed that in the group of boys, the strength of the muscles, but not the endurance, had an influence on academic performance. On the other hand, in the group of girls, muscle strength and endurance had an influence on school performance. Summarizing all 4 components of physical fitness tested by Wang et al. [43], the authors stated that, in the case of girls, any type of exercise included in the study has a positive effect on academic performance. However, in the case of boys it was true only in the field of muscle strength and cardiorespiratory fitness.

The results of the presented studies show that the relationship between the components of muscle performance and academic performance requires further research, primarily interventional studies concerning factors that have the greatest impact on muscle performance and academic performance. Future research in this area should also focus on when is the best time to introduce interventions leading to increased muscle strength and endurance. It is also important to examine the relationship between the time of intervention and the impact on muscle strength and endurance and academic performance.

The explanation of these issues may have a practical aspect in the future, allow for the introduction of program changes in physical education lessons, and act as a guide for teachers in modifying school and/or extracurricular activities.

\section{Conclusions}

Physical fitness has irreplaceable health benefits, maintaining, strengthening, or improving good health. It is a factor of great importance in shaping the proper development of children and adolescents, as well as the main stimulator of psychomotor development. Adapted to the needs of the body, it increases its overall efficiency, increases muscle mass and increases endurance and resistance to negative effects $[22,39,41]$. As the above review shows, physical fitness may also bring benefits in learning effectiveness. It is still worth performing further research in this area, and it is certainly worth considering the inclusion of more aerobic exercise, increasing cardiorespiratory fitness in the school program. Moreover, it seems important to influence other components of physical fitness such as flexibility and muscle strength in this area. Understanding the relationship between individual components of physical fitness and academic performance can become the basis for introducing modifications to school programs, that is, planning a physical education program and extracurricular sport activities that could contribute to the effectiveness of teaching.

The above review also showed that the analyzed relationship between components of physical fitness such as flexibility, strength, and muscle endurance and cardiorespiratory fitness remains uncertain and further research in this area is necessary. Not all research results are unambiguous, which may be due to differences in methodology. In some studies, school grades were used to measure academic performance, and in others, language and mathematics tests were used to measure school performance. Researchers also pay attention to the importance of gender in this area. Examining its impact and assessing its significance may make it necessary to introduce differences in the scope of exercises for girls and boys in order to increase the efficiency of learning.

Taking into consideration the health benefits of physical fitness for students' health, the role of physical education and extracurricular sport activities should not be underestimated. It may be associated not only with health benefits but also with better academic performance. This confirms that physical activity is extremely important in the school curriculum and the number of hours of physical education should not be reduced in favor of other classes, but rather the quality of physical education lessons should be enhanced. Another issue to consider is the fact that various components of physical fitness have different intensity of physical activity, which can differently affect academic performance.

Conflict of interest: Authors state no conflict of interest.

\section{References}

1. Akpınar E., Yıldız E., Tatar N., Ergin Y.F. (2009) Students' attitudes toward science and technology: an investigation of gender, grade level, and academic achievement. Procedia Soc. Behav. Sci., 1(4): 2804-2808. DOI: 10.1016/j.sbspro.2009.01.498.

2. Bass R.W., Brown D.D., Laurson K.R., Coleman M.M. (2013) Physical fitness and academic performance in middle school students. Acta Paediatr., 12: 832-837. DOI: 10.1111/apa.12278.

3. Benson A.C., Torode M.E., Fiatarone Singh M.A. (2006) Muscular strength and cardiorespiratory fitness is associated with higher insulin sensitivity in children and 
adolescents. Int. J. Pediatr. Obes., 1(4): 222-231. DOI: 10.1080/17477160600962864.

4. Bezold C.P., Konty K.J., Day S.E., Berger M., Harr L., Larkin M., Napier M.D., Nonas C., Saha S., Harris T.G., Stark J.H. (2014) The effects of changes in physical fitness on academic performance among New York City youth. J. Adolesc. Health, 55: 774-781. DOI: 10.1016/j. jadohealth.2014.06.006.

5. Biddle S.J., Asare M. (2011) Physical activity and mental health in children and adolescents: a review of reviews. Br. J. Sports Med., 45(11): 886-895. DOI: 10.1136/ bjsports-2011-090185.

6. Chaddock-Heyman L., Erickson K.I., Kienzler C., King M., Pontifex M.B., Raine L.B., Hillman C.H., Kramer A.F. (2015) The role of aerobic fitness in cortical thickness and mathematics achievement in preadolescent children. PLoS ONE, 10(9): e0134115.

7. Chaddock L., Erickson K.I., Prakash R.S., Voss M.W., VanPatter M., Pontifex M.B, Hilman C.H., Kramer A.F. (2012) A functional MRI investigation of the association between childhood aerobic fitness and neurocognitive control. Biol. Psychol., 89(1): 260-268. DOI: 10.1016/j. biopsycho.2011.10.017.

8. Chomitz V.R., Slining M.M., McGowan R.J., Mitchell S.E., Dawson G.F., Hacker K.A. (2009) Is there a relationship between physical fitness and academic achievement? Positive results from public school children in the northeastern United States. J. Sch. Health, 79: 30-37.

9. Davis C.L., Cooper S. (2011) Fitness, fatness, cognition, behavior, and academic achievement among overweight children: Do cross-sectional associations correspond to exercise trial outcomes? Prev. Med., 52(1): 65-S69. DOI: 10.1016/j.ypmed.2011.01.020.

10. Donnelly J.E., Greene J.L., Gibson C.A., Smith B.K., Washburn R.A., Sullivan D.K., DuBose K., Mayo M.S., Schmelzle K.H., Ryan J.J., Jacobsen D.J, Williams S.L., (2009) Physical Activity Across the Curriculum (PAAC): a randomized controlled trial to promote physical activity and diminish overweight and obesity in elementary school children. Prev. Med., 9(4): 336-341. DOI: 10.1016/j.ypmed.2009.07.022.

11. Donnelly J.E., Hillman C.H., Castelli D., Etnier J.L., Lee S., Tomporowski P., Lambourne K., SzaboReed A.N., (2016) Physical Activity, Fitness, Cognitive Function, and Academic Achievement in Children: A Systematic Review. Med. Sci. Sports Exerc., 48(6): 1197-1222. DOI: 10.1249/MSS.0000000000000901.

12. Dwyer T., Sallis J.F., Blizzard L., Lazarus R., Dean K., (2001) Relation of Academic Performance to Physical Activity and Fitness in Children. Pediatr. Exerc. Sci., 13(3): 225-237.

13. Global Recommendations on Physical Activity for Health. Geneva: World Health Organization, (2010).
14. Gonzales M.M., Tarumi T., Miles S.C., Tanaka H., Shah F., Haley A.P. (2010) Insulin sensitivity as a mediator of the relationship between BMI and working memory-related brain activation. Obesity, 18(11): 2131-2137. DOI: $10.1038 /$ oby.2010.183.

15. Haapala E.A. (2013) Cardiorespiratory fitness and motor skills in relation to cognition and academic performance in children - a review. J. Hum. Kinet., 36: 55-68. DOI: 10.2478/hukin-2013-0006.

16. Hillman C.H., Buck S.M., Themanson J.R., Pontifex M.B., Castelli D.M. (2009) Aerobic fitness and cognitive development: event-related brain potential and task performance indices of executive control In preadolescent children. Dev. Psychol., 45(1): 114-129. DOI: 10.1037/a0014437.

17. Hillman C.H., Castelli D.M., Buck S.M. (2005) Aerobic fitness and neurocognitive function in healthy preadolescent children. Med. Sci. Sports Exerc., 37(11): 1967-1974. DOI: 10.1249/01.mss.0000176680.79702.ce.

18. Hillman C.H., Erickson K.I., Kramer A.F. (2008) Be smart, exercise your heart: exercise effects on brain and cognition. Nat. Rev. Neurosci., 9(1): 58-65. DOI: 10.1038/ nrn2298.

19. Hillman C.H., Pontifex M.B., Castelli D.M., Khan N.A., Raine L.B., Scudder M.R., Drollette E.S., Moore R.D., Wu C.T., Kamijo K. (2014) Effects of the FITKids randomized controlled trial on executive control and brain function. Pediatrics, 134(4): 1063-1071. DOI: 10.1542/ peds.2013-3219.

20. Hillman C.H., Pontifex M.B., Motl R.W., O’Leary K.C., Johnson C.R., Scudder M.R., Raine L.B., Castelli D.M., (2012) From ERPs to academics. Dev. Cogn. Neurosci., 2: 90-98. DOI:10.1016/j.den.2011.07.004.

21. Huang T., Tarp J., Domazet S.L., Thorsen A.K., Froberg K., Andersen L.B., Bugge A. (2015) Associations of adiposity and aerobic fitness with executive function and math performance In Danish adolescents. J. Pediatr., 167(4): 810-815. DOI: 10.3410/f.725708845.793509610.

22. Janssen I., Leblanc A.G. (2010) Systematic review of the health benefits of physical activity and fitness in schoolaged children and youth. Int. J. Behav. Nutr. Phys. Act., 7(1): 40. DOI: 10.1201/b18227-14.

23. Kamijo K., Khan N.A., Pontifex M.B., Scudder M.R., Drollette E.S., Raine L.B., Evans E.M., Castelli D.M., Hillman C.H. (2012) The relation of adiposity to cognitive control and scholastic achievement in preadolescent children. Obesity (Silver Spring), 20(12): 2406-2411. DOI: 10.1038/oby.2012.112.

24. Kao S.C., Westfall D.R., Parks A.C., Pontifex M.B., Hillman C.H. (2017) Muscular and Aerobic Fitness, Working Memory, and Academic Achievement in Children. Med. Sci. Sports Exerc., 49(3): 500-508. DOI: 10.1249/ MSS.0000000000001132. 
25. Keeley T.J.H., Fox K.R. (2009) The impact of physical activity and fitness on academic achievement and cognitive performance in children. Int. Rev. Sport Exerc. Psychol., 2(2): 198-214. DOI: 10.1080/17509840903233822.

26. Kwak L., Kremers S.P.J., Bergman P., Ruiz J.R., Rizzo N.S., Sjöström M. (2009) Associations between Physical Activity, Fitness, and Academic Achievement. J. Pediatr., 155: 914-918. DOI: 10.1016/j.jpeds.2009.06.019.

27. Novello A.C., Degraw C., Kleinman D. (1992) Healthy children ready to learn: An essentials collab oration between health and education. Public Health Reports, 107(1): 3-15.

28. Moore R.D., Drollette E.S., Scudder M.R., Bharij A., Hillman C.H. (2014) The influence of cardiorespiratory fitness on strategic, behavioral, and electrophysiological indices of arithmetic cognition In preadolescent children. Front Hum. Neurosci., 8: 258. DOI: 10.3389/ fnhum.2014.00258.

29. Moore R.D., Wu C.T., Pontifex M.B., O’Leary K.C., Scudder M.R., Raine L.B., Johnson C.R., Hillman C.H. (2013) Aerobic fitness and intra-individual variability of neurocognition in preadolescent children. Brain Cogn., 82(1): 43-57. DOI: 10.1016/j.bandc.2013.02.006.

30. Oliveira T., Pizarro A., Costa M., Fernandes L., Silva G., Mota J., Ribeiro J.C. (2017) Cardiorespiratory fitness, but not physical activity, is associated with academic achievement in children and adolescents. Ann. Hum. Biol., 44(4): 309-315.

31. Ortega F.B., Ruiz J.R., Castillo M.J., Sjöström M. (2008) Physical fitness in childhood and adolescence: a powerful marker of health. Int. J. Obes., 32: 1-11.

32. Pindus D.M., Drollette E.S., Scudder M.R., Khan N.A., Raine L.B., Sherar L.B., Esliger D.W., Kramer A.F., Hillman C.H. (2016) Moderate-to-vigorous physical activity, indices of cognitive control, and academic achievement in preadolescents. J. Pediatr., 173: 136-142. DOI: 10.1016/j.jpeds.2016.02.045.

33. Rosenbaum D.A., Carlson R.A., Gilmore R.O. (2001) Acquisition of intellectual and perceptual-motor skills. Annu. Rev. Psychol., 52: 453-470. DOI: 10.1146/annurev. psych.52.1.453.

34. Santana C.C.A., Azevedo L.B., Cattuzzo M.T. (2017) Physical fitness and academic performance in youth: A systematic review. Scand. J. Med. Sci. Sports, 27(6): 579-603. DOI: 10.1111/sms.12773.

35. Sardinha L.B., Marques A., Martins S., Palmeira A., Minderico C. (2014) Fitness, fatness, and academic performance in seventh-grade elementary school students. BMC Pediatrics, 14: 176.

36. Scudder M.R., Federmeier K.D., Raine L.B., Direito A., Boyd J.K., Hillman C.H. (2014) The association between aerobic fitness and language processing in children: implications for academic achievement. Brain Cogn., 87: 140-152. DOI: 10.1016/j.bandc.2014.03.016.

37. Scudder M.R., Khan N.A., Lambourne K., Drollette E.S., Herrmann S.D., Betts J.L., Washburn R.A., Donnelly J.E., Hillman C.H. (2015) Cognitive control in preadolescent children with risk factors for metabolic syndrome. Health Psychol., 34(3): 243-252. DOI: 10.1037/hea0000114.

38. Singh A., Uijtdewilligen L., Twisk J.W., van Mechelen W., Chinapaw M.J. (2012) Physical Activity and Performance at School: a Systematic Review of the Literature Including a Methodological Quality Assessment. Arch. Pediatr. Adolesc. Med., 166(1): 49-55. DOI: 10.1001/archpediatrics.2011.716.

39. Smith J.J., Eather N., Morgan P.J., Plotnikoff R.C., Faigenbaum A.D., Lubans D.R. (2014) The health benefits of muscular fitness for children and adolescents: a systematic review and meta-analysis. Sports Med., 44(9): 1209-1223. DOI: 10.1007/s40279-014-0196-4.

40. Thompson W.R., Gordon N.F., Pescatello L.S. (2010) ACSM's guidelines for exercise testing and prescription. Wolters Kluwer/Lippincott Williams \& Wilkins, Philadelphia.

41. Trudeau F., Shephard R.J. (2008) Physical education, school physical activity, school sports and academic performance. Int. J. Behav. Nutr. Phys. Activ., 5: 10. DOI: 10.1186/1479-5868-5-10.

42. Van Dusen D.P., Kelder, S.H., Kohl H.W., Ranjit N., Perry C.L. (2011) Associations of physical fitness and academic performance among schoolchildren. J. Sch. Health, 81: 733-740. DOI: 10.1111/j.1746-1561.2011.00652.x.

43. Wang K.M., Wang P.S., Huang Y.C. (2012) Physical Fitness and Academic Achievement of Elementary School Students: a cross-sectional survey in Southern Taiwan. J. Phys. Educ. Sport, 12(3): 302-309. DOI: 10.7752/ jpes.2012.03045.

44. Wittberg R., Cottrell L.A., Davis C.L., Northrup K.L., (2010) Aerobic Fitness Thresholds Associated with Fifth Grade Academic Achievement. Am. J. Health Educ., 41(5): 284-291.

\section{Received 25.04.2018 \\ Accepted 19.11.2018}

(C) University of Physical Education, Warsaw, Poland

\section{Acknowledgments}

We apologize to all authors whose contribution to this field of research was not cited/included owing to space restrictions. 